\title{
Negotiating Gender in the English Football Workplace: Composite Vignettes of Women Head Coaches' Experiences
}

\author{
Beth G. Clarkson \\ University of Portsmouth
}

\author{
Elwyn Cox \\ University of Winchester
}

\author{
Richard C. Thelwell \\ University of Portsmouth
}

\begin{abstract}
Historically, men have dominated the English football workplace; as a result, the number of women in coaching positions has been limited. The aim of the present study was to explore the lived experiences of women head coaches to identify the extent that gender influences the English football workplace. Semi-structured interviews $(N=12)$ were conducted with women head coaches operating at the (a) youth recreational, (b) talent development, and (c) elite levels of the English football pyramid. An inductive thematic analysis was performed which informed the development of composite vignettes, a form of creative nonfiction. Three vignettes were developed comprising women head coaches' stories at each pyramid level. Findings from the thematic analysis identified themes of gender stereotyping, proving yourself, and confidence at the youth recreational level; work-life conflicts, limited career mobility, and marginalization at the talent development level; and tokenism, undercurrents of sexism, and apprehensions of future directives at the elite level. The vignette stories demonstrate that gender negatively influences coaches' interactions and confidence early in their career in youth recreational football; gender bias is embedded within discriminatory organizational practices which limit career mobility for coaches working in talent development; and gender is used to hold elite level women coaches to higher scrutiny levels than male colleagues. Recommendations (e.g., [in]formal mentoring, male advocacy, recruitment transparency) are made to practitioners for a targeted occupational-focused approach regarding support, retention, and career progression of women head coaches in football.
\end{abstract}

Keywords: coaching, female, leadership, underrepresentation

\section{Background}

In stark contrast to a significant growth in women's participation in football (soccer) over the past 20 years, such growth is not reflected in the number of women coaches at all levels of expertise (Williams, 2013). Recent reports indicate that $80 \%$ of coaching positions in European women's football are held by men (Union of European Football Associations, 2015). Archival analysis of data on teams participating in the Union of European Football Associations (UEFA) Women's Champions League has revealed only 23 head coaches to be women, compared to $147 \mathrm{men}$, since the competition began in 2011 (Filho \& Rettig, 2018). In England, women are even less likely to hold coaching positions; men hold $91 \%$ of all coaching jobs in women's football (Union of European Football Associations, 2017). There are no women head coaches in men's professional football (Rudd, 2018) and only one woman head coach in men's semi-professional football (Wrack, 2018). Statistically, compared to men, women are a marginalized group represented by a proportionately low number in head coaching positions, which does little to change perceptions that football is fiercely masculine or to inspire women to believe coaching is a realizable career (LaVoi, 2016; Norman, 2014). Given the proliferation of women's participation, why are there so few women head coaches in football?

A rich body of research has documented this underrepresentation of women in sports coaching (see for a review, Burton,

Clarkson and Thelwell are with the School of Sport, Health, and Exercise Science, University of Portsmouth, Portsmouth, United Kingdom. Cox is with the Department of Sport, Exercise, and Health, University of Winchester, Winchester, United Kingdom. Clarkson (beth.clarkson@port.ac.uk) is corresponding author.
2015). LaVoi and Dutove's (2012) model of barriers (and supports) for women coaches organizes challenges that women coaches face in an ecological model from the most proximal (i.e., individual) to distal levels (i.e., sociocultural). A number of complex and dynamic barriers within this framework that impede women in coaching have been identified in extant literature at individual (e.g., coach burnout; Durand-Bush, Collins, \& McNeill, 2012), interpersonal (e.g., work-family conflict; Dixon \& Bruening, 2007), organizational (e.g., lack of training opportunity; Shaw \& Allen, 2009), and sociocultural levels of analysis (e.g., homophobic climate of sport; Cunningham \& Sagas, 2003). In their updated review of research, Burton and LaVoi (2016) called for a focus of attention away from the individual and interpersonal levels of analysis towards influencing change at the organizational and sociocultural level. Moreover, Norman, Rankin-Wright, and Allison (2018) argued underrepresentation of women coaches must be reframed as "a symptom, or an outcome of a deeper issue, rather than the problem in itself' (p. 395). Hence, this study sought to examine the organizational (i.e., organizational policies and professional practices) and sociocultural context (i.e., social norms and cultural systems) that women football coaches operate within to understand why in England they hold only $9 \%$ of head coaching jobs in women's football.

\section{The History and Development of Women and Football in England}

Football is known as England's national sport, but has shown itself to be associated with hegemonic masculinity, endorsement of conservative attitudes, and the exclusion of women (Fishwick, 1989; Tomkins, 1993). A turbulent history of women in English 
football exists. Women were excluded by The Football Association (FA) from participation with affiliated clubs and at football grounds in 1921 after being declared unsuitable for the game (Williams, 2013). Preceding the ban, matches between women's factory teams, formed during World War I (1914-1918), regularly attracted crowds in the tens of thousands and women's football was in robust health (Newsham, 1994). Women's exclusion lasted for over four decades and was argued to be part of the FA's deliberate attempt to restrict women's performance of gender to traditional visions of a woman's role, and recoup the masculine image of football, which had been lost during the war (Newsham, 1994; Williams, 2003).

Women footballers consequently became invisible, with their popularity, knowledge, and skills lost as a result of exclusion from organized competition. The women's game became quickly overshadowed by the growth of the professionalized men's game. Under pressure from UEFA in the early 1970s, the FA rescinded their ban and the Women's Football Association governed women's football until its dissolution in 1993 when power was transferred to the FA (The Culture, Media, and Sport Committee, 2006). However, the social taboo of women's participation in football lingered in subsequent years, and the sport centered on the participation growth rather than the commercialization, spectator support, and media interest that had rapidly grown in men's football during the period of the ban (Williams, 2003).

Women's football has been fast growing with figures showing that the number of registered players increased from 10,000 in 1993 when records began, to 2,050,000 in 2017 (Football Association, 2017b). Women's football, however, continues to experience a significant image problem in English football culture, with female players repeatedly experiencing gender discrimination and stereotypical attitudes (Scraton, Fasting, Pfister, \& Bunuel, 1999). Despite these challenges, women's elite-level football has evolved in the past 20 years from an amusing eccentricity to full professionalization of the top-tier of women's football (Football Association, 2017a; Williams \& Woodhouse, 1991). The FA's England girls' talent pathway supports the identification and development of elite players at different stages of the football pyramid: from community clubs at the bottom, through Regional Talent Clubs (RTCs) and regional development programs, to national performance camps and international selection at the top.

\section{Research With Women Coaches in Football}

While a large body of literature has examined the underrepresentation of women in sports leadership, sports-specific investigations into the professional challenges facing women coaches have been scarce. Given the cultural significance of football in England and its deeply masculinized history, it is imperative that research focuses on the organizational and sociocultural contexts in which women in football operate. Emerging research has demonstrated that multiple informal factors prevent women coaches' full unpermitted access to the football workplace (e.g., Lewis, Roberts, \& Andrews, 2018; Norman et al., 2018). Informal and deep-rooted cultural bias presents a range of pressures for women coaches, despite formal barriers to women coaches' entry to English football (e.g., governing body policy) having long been removed. For example, Lewis et al. (2018) identified the cultural practices of men coach educators and candidates as disparaging towards women and reinforcing of gender stereotypes. Women coaches interviewed by Lewis et al. (2018) reported being met with hostility and treated like an outsider on the FA's coach education courses, and that as a result they felt a "lack of self-worth" (p. 33). Coach educators can be effective in preventing women from striving towards a career in coaching by engaging in cultural practices that stem from patriarchal habitus (i.e., ingrained habits), such as the devaluing of women's social stature on courses (Bourdieu, 1986; Lewis et al., 2018). While Lewis and colleagues' (2018) study has stimulated discussion of the difficulties faced by women in coach education provision, research has failed to extend this knowledge and illuminate the lived experiences of women football coaches in their places of work.

Research demonstrates that women perceive the coach education atmosphere in England to be intimidating and uncomfortable, despite the FA's own guidelines for respect and fair play (Football Association, 2014). This finding suggests national governing bodies' (NGBs) employees play a pivotal role in the implementation of equality policies. In an analysis of organizational culture in the FA, Norman and colleagues (2018) conducted interviews with women coaches and women coach educators and identified three tenets that have salient influences on their experiences, retention, development, and progression: inclusive leadership, supportive and horizontal relationships, and visible pathways for career development were most influential. Women who felt most supported in their career progression worked in central or regional FA roles, whereas women coaches operating outside of the organization were left feeling frustrated by a lack of access to continued professional development. Women coaches' experiences, therefore, do not appear equitable in the football workplace, suggesting gender as an influential factor in a coach's career growth. At present, negligible attention has been given to organizational differences in how gender is experienced by women coaches operating at different levels of the football pyramid. Are difficulties felt most by women at the start of their career at the recreational youth level and felt less later in their career when ingratiated within its culture through talent development and elite levels?

Due to the limited nature of investigations concerning women football coaches, researchers can look to scholarly investigations of women in non-playing support roles (e.g., coordinators, secretaries, treasurers) to signify the challenges facing women football coaches. Active resistance by men to women's presence, pressure to conform to masculine ideals, construction of women's work as inferior to male counterparts, and hidden femininity have been theorized as 'invisible' factors impeding women's position in football (e.g., Fielding-Lloyd \& Meân, 2008, 2011; Welford, 2011). These factors serve to maintain men's entitlement to central membership of football and position women at the peripheries of the sport. Such practices as these inhibit women's coaching ability and opportunities to realize their full potential within their career trajectory.

Men are more likely to respect women and view them as equals when exposed to competent women leaders (Fink, LaVoi, \& Newhall, 2016). Role congruity theory of prejudice proposes that attitudes are less positive toward female than male leaders when there is perceived incongruity between the female gender role and leadership roles (Eagly \& Karau, 2002). Women coaches are more present at lower levels of the football pyramid where it is reasonable to assume the strength of dominant discourses (i.e., discourses that affect relations and create forms of dominance) are less prominent than at higher levels where women coaches do not have much exposure (Union of European Football Associations, 2017). Hence, it is likely that the extent to which women coaches negotiate gender in the football workplace will be largely determined by the context of the organization and the level of the football pyramid in which they operate. 


\section{The Present Study}

With literature suggesting an existence of sexist and disparaging language, behavior, and cultural practices towards women in English football culture, further attention is required to comprehend the organizational and sociocultural factors at play for several reasons. First, there is limited knowledge of the football coaching workplace, and further examination will importantly extend our understanding of how women coaches operate in this sport, given its deeply masculinized history. Second, a dearth of knowledge exists concerning the pervasiveness of gender inequality facing women head coaches in their navigation of gender in different roles across the football pyramid. Taking an occupational-focused approach will extend our understanding of whether barriers that women coaches face are consistent or differ in specific organizational areas (i.e., youth recreational, talent development, and elite level) and better inform practice and future research. Third, this study responds to the call made by Burton and LaVoi (2016) to add knowledge of organizational and sociocultural factors that impede women sports coaches. Therefore, the aim of the present study was to explore the lived experiences of women football head coaches operating at multiple levels of the football pyramid in England to illuminate the pervasiveness of gender in the football workplace.

\section{Theoretical Framework}

Connell's (1987) hegemonic masculinity theory has been adopted as a lens to study sociocultural inequalities within the football context. Hegemonic masculinity is situated as a sociocultural barrier in LaVoi and Dutove's (2012) ecological model. Drawing on Gramsci's (1971) notion of cultural hegemony (i.e., the dominance of one social group over others), Connell contends that hegemonic masculinity is a pattern of practice (i.e., engaged activities, not just an identity or role expectations) that can be characterized by acts which reinforce male privilege, support conformity to an idealized version of masculinity, and subordinate women in order to maintain the system of patriarchy (Bryson, 1987; Connell \& Messerschmidt, 2005). The ban of women from organized participation in football is seen as an early expression of hegemonic masculinity, and male dominance in English football continues to be evidenced by the emphasis of masculine ideals in the sport by the media (Caudwell, 2011), underrepresentation of women in decision-making positions (Women in Sport, 2016), and the absence of women in coaching positions (Welford, 2011). Women's historical absence and men's privileged and dominant positions in football facilitate the sport as a site for male hegemony. The research reviewed in this study shows women's participation in football has increased, but women coaches fight against patriarchal norms. Further examination through the hegemonic masculinity lens is required to fully uncover how powerful gender bias is in the football workplace and if male hegemony thrives across all levels of the football pyramid. LaVoi and Dutove's (2012) ecological model was also used to underpin the examination of organizational and sociocultural barriers and supports to women coaches.

\section{Methods}

\section{Philosophical Assumptions}

Critical inquiry underpinned this study: we hold that ideas are mediated by power relations in society, certain groups are privileged over others, and that researchers are responsible for a critical stance towards the culture they are exploring (see Smith \& Sparkes,
2016). In line with this philosophical stance, we believe that the investigator and participant are interactively linked and create findings together and as such, qualitative creative non-fiction methods were employed to provide in-depth accounts of the head coaches' lived experiences and give precedence to the female voice (Reinharz \& Davidman, 1992). Particular emphasis was placed on how to balance approaches which stress the central role of participants' knowledge with the expert knowledge of the researchers. Rather than engage in recently criticized member checking, inter rater reliability, or universal criteria methods for establishing rigor in qualitative research, rigor was developed via member reflections where the participant and researcher explore the findings to generate additional insight (Smith \& McGannon, 2018). Member reflections differ from member checks as they are less a test of research findings as they are an opportunity to engage in collaboration and reflexive elaboration (Tracy, 2010). The interpretation of findings was discussed with a subsample of participants (i.e., one head coach per vignette) to identify any gaps or disagreement in the results. Participants' voices were prioritized over the researchers. No disagreements were found, and minor additions were made to the vignettes to fully illuminate stories.

\section{Participants}

Participants were purposively drawn from the population of women actively coaching football in England. Head coaches operating in English football were purposively targeted as participants due to the relevance of this governance context to the study purpose. Twelve head coaches volunteered to take part in the study. The sample comprised women who identified as White British (84\%), Black British (8\%), and Mixed-Race British (8\%). Participants were categorized as either operating in youth recreational level (i.e., coaching in recreation football; $n=5$ ), talent development level (i.e., coaching in youth academy football; $n=4$ ), or elite level (i.e., coaching in adult professional football; $n=3$ ). Eleven participants were head coaches of girls' or women's football teams and one participant coached an elite boy's academy team in a men's professional football club. The inclusion in the sample of one woman head coach working in men's football was not only appropriate but also could be argued representative of the women coaching population working in men's sports; research from North America reports only 2\% of all men's sports team coaches to be women (Reade, Rogers, \& Norman, 2009). Head coaches had from 2 to 15 years experience $(M=6.00$ years) with combined football coaching experience of 72 years. ${ }^{1}$ The highest level of obtained coaching qualification of the participants was FA Level 4 in coaching football (i.e., UEFA A license; $n=1$ ), FA Level 3 in coaching football (i.e., UEFA B license; $n=4$ ), FA Level 2 in coaching football (i.e., UEFA C license; $n=5$ ), and FA Level 1 in coaching football $(n=2)$. Participants' ages ranged from 20-38 years old $(M=28.67$ years). All head coaches delivered a minimum of two training sessions per week with either one or more teams and attended match days. Coaching was the full-time occupation for only three coaches; the majority of head coaches supplemented their coaching with additional work duties, which were: community department staff in professional men's football clubs $(n=2)$, physical education teacher $(n=2)$, futsal coaching business owner $(n=1)$, university lecturer $(n=1)$, county FA development officer $(n=1)$, and students in higher education studies $(n=2)$. The athletic achievement of the participants was diverse, comprising current or ex-local league-level players $(n=3)$, ex-youth academy players $(n=5)$, exdomestic professional adult players $(n=3)$, and an ex-international professional adult player $(n=1)$. 


\section{Procedure}

To engage in fully reflexive research, researchers must consider how their own positions in the world influence the way in which they perceive it (Temple \& Young, 2004). The lead author identifies as a White woman and as a Level 3 qualified football coach with 12 years' coaching experience. The lead author had not experienced overt sexism in her coaching practice but upon reflection had experienced subtle sexism in the form of odd looks and lack of conversation from male colleagues (i.e., sexism that can be either hidden or unnoticed because it is built into cultural and societal norms). Anecdotally, the lead author had heard of such overt instances from fellow women head coaches, which had initially stimulated interest in understanding the scope of gender in the football workplace. Her positionality made her suitable to be viewed as an "insider" to research participants (McCorkel \& Myers, 2003). To limit issues of positionality (i.e., author bias or assumptions that might shape the research process), the research team regularly engaged in discussions about the framing of interview questions and data representation from a position of neutrality. We were forthright in communicating positionality with participants, and cognizant not to assume gender bias in the football workplace (Bourke, 2014).

Following institutional ethical approval, head coaches were approached by the lead researcher based on personal associations and invited to participate in a one-to-one interview with the lead researcher. There was no prior knowledge regarding whether the head coaches had experienced sexism in the workplace. A semistructured interview guide was developed to facilitate interviews and divided into two sections: (a) football coaching experiences (e.g., "can you recall any critical periods in your life that have been important in your coaching career?") and (b) experiences of being a woman head coach in a male-dominated sport (e.g., "to what extent have you ever experienced any negative attitudes towards you as a woman head coach based on your gender?"). Questions constructed by the lead researcher in line with the research question and extant literature were examined by the second and third author to determine their appropriateness. To facilitate the flow of the semi-structured interviews, probes (e.g., "could you expand on what you mean by [the issue]") and elaborations (e.g., "could you explain [the issue] in more detail") were incorporated. Individual interviews were conducted either in person or on the telephone at a time of the participants' choosing. Although face-to-face interviews have been described as the "gold standard" for qualitative research (McCoyd \& Kerson, 2006, p. 389), there is little evidence that data loss or distortion occurs in telephone interviews and that enabled us to reach a geographically dispersed population (Novick, 2008). Therefore, telephone interviews were offered to coaches unable to participate in face-to-face interviews. Interviews lasted between 44 and 69 minutes $(M=55.18, S D=7.78)$ and, once transcribed verbatim, generated 85 pages of single-spaced text. Each participant was sent an interview transcript to verify accuracy before data analysis commenced. No changes were required.

\section{Data Analysis and Representation}

Considering the potentially sensitive nature of the stories told, participants' accounts were developed into composite vignettes, a form of creative nonfiction. Identities were protected by the composition of a synthesized account of multiple interwoven individuals' stories (Smith, 2013). Secure anonymity enabled the contributors to speak freely and fully in their discourses. A two-stage data analysis procedure was followed. An interpretative thematic analysis was conducted in the first stage to act as a foundation for the second stage of analysis, the development of composite vignettes used to reconstruct the participants' stories. A key advantage of this novel research approach is the ability to facilitate new understandings of the organizational and sociocultural issues that shape women coaches' navigation of gender in the football workplace by holistically sharing the complexity and nuances of participants' lived experiences. These experiences are likely to resonate with a diverse audience (e.g., coaches, managers, players, and practitioners) and invoke a greater sense of reflection than other qualitative research techniques (Schinke, Blodgett, McGannon, \& Ge, 2016). Creative nonfiction practices, whereby the authors move from story analysts to story tellers, have been advocated by qualitative researchers (e.g., Schinke et al., 2016) in line with scholarly investigations into the professional challenges of sports scientists (e.g., Hings, Wagstaff, Anderson, Gilmore, \& Thelwell, 2018) and cultural dynamics in athlete transitions (e.g., Schinke et al., 2016).

\section{Stage One: Thematic Analysis}

In the first phase, Braun and Clarke's (2006) six-stage model for data-driven thematic analysis was followed to identify, describe, and interpret patterns across the dataset. Audio recorded interviews were transcribed verbatim and anonymized, and then the authors independently immersed themselves in the data, reading interview transcripts several times. The data were entered into NVivo 11 qualitative data analysis software (QSR International Pty Ltd, 2015), and explicitly stated meanings expressed in the data were then systematically coded. Next, a process of theme development, refinement, and naming was conducted to cluster codes and distinguish themes. Each higher-order theme was convened around a central organizing concept to ensure its coherence and meaningfulness (Braun, Clarke, \& Weate, 2016). Themes generated were reviewed and then comprehensively defined. Lastly, the themes' broader meanings and implications were scrutinized to theorize their significance to the research question. All themes were used to structure the content of the vignettes.

\section{Stage Two: Creative Non-Fiction}

The second stage of data analysis involved a creative analytic practice (CAP) known as creative nonfiction. This new qualitative research method is grounded in empirical data but uses creative writing techniques to resonate with readers (Schinke et al., 2016). Using stories is a powerful way to reveal complexities within sporting environments (e.g., Hings et al., 2018), and creative nonfiction can be used to share real-life events and illuminate subjectivities, complexities, and fluidities in lived experiences (Smith, 2013). Such forms of narrative inquiry have been promoted by sport management scholars in recent years as a way of reaching wider audiences (e.g., Hoeber \& Shaw, 2017; Stride, Fitzgerald, \& Allison, 2017).

\section{Composite Vignettes}

Overarching themes from the first analysis stage were used to structure the content of the vignettes. Each composite vignette provided one synthesized account from multiple individuals combining their experiences from the participant perspective, drawing upon the empirical data that was systematically gathered to move the reader towards a deeper understanding of the topic (Smith, McGannon, \& Williams, 2015). Key phrases and stories were extracted from the interview transcripts to best represent each 
theme, with the inclusion of as many direct quotes as possible to maintain the participants' spoken words. Phrases and stories were then merged together to ensure a natural flow to each vignette with a coherent and powerful account rich in description (Smith et al., 2015). Once fully formed, the vignettes were independently reviewed by each author against the interview transcripts to check that no information had been misrepresented.

After the authors re-read the interview transcripts, intersecting views emerged among participants in similar occupational areas and at similar stages in their career, as well as diverging accounts between those at different occupational areas and points in their career. A categorization approach was adopted whereby the identification and grouping together of classifying features formed typologies (e.g., Christensen, 2013), resulting in the composition of three vignettes that told the separate stories of a youth recreational head coach $(n=5)$, a talent development head coach $(n=4)$, and an elite level head coach $(n=3)$. While some overlap in themes emerged between participants at different levels of the football pyramid (e.g., confidence was a prominent theme at the recreational level but also mentioned, to a lesser extent, at the talent development level), themes were categorized to a particular level of the football pyramid only when common amongst all participants at that level and with enough data to support them (Braun \& Clarke, 2006).

\section{Results}

\section{Introduction to the First Vignette: Gender Stereotyping, Having to Prove Yourself, and Confidence}

In the first vignette, experiences of gender stereotyping in interactions with players and colleagues, having to prove competence to gain respect, and the negative impact of those interactions on wellbeing are explored. Contributors in this vignette described experiences of exclusion early in their careers, resistance to women's increased presence, the constant necessity to prove claim to membership of the coaching workforce and the impact on their confidence. It tells the story of Janet, a recreational head coach with three years of coaching experience with girls' and boys' teams at a localleague club. Janet started coaching while at university where she was able to access university financial bursaries and fund her first coaching qualification.

Janet: A Youth Recreational Head Coach's Story (Early Career). Up until a couple of years ago, I did not think it was even possible for women to become football head coaches; as a player I had never met a professional woman coach. To develop into the best head coach I can be, I know I need to be able to adapt to different environments and to coach both boys and girls. I feel confident coaching the girls' team, but I am struggling to feel the same way with the boys' team. It would be easier for me to be an assistant coach. I cannot express myself with male players in the same way I can with female players. I feel judged on my ability to head coach because of my gender. Male players at our club just do not give me as much respect as much as they do to their other (male) head coach. For example, I arrived in my first week to give the pregame team talk to little comments from the players: "Are you here to clean our boots after the match?" and "it should be you who washes our kit." I felt completely put on the spot and did not know what to say. In the first training session the following week I demonstrated a skill in training and one of the players said: "wow, a girl just kicked a ball." I have played football for 12 years of my life, but because of that one comment I felt I should not be kicking a ball at all. I remember it really made me wonder whether I was good enough to be a head coach. Confidence has such a big impact on my coaching at the moment.

It is really important to me that in recreational football girls' and boys' teams are treated equally. When I was younger, the boys' teams got all the club's resources, equipment, and support, and the girls' teams were lucky to get what was left. I do not want my girls to grow up being treated second best and experience those same obstacles. I get frustrated that I have to fight for them in that way; I do not have to for my boys' team-it is a given. At committee meetings, the male head coaches can be a little patronizing. It is little comments like "oh, I am surprised you have managed to get the match on," and I will just think why are you surprised? The members of the committee also call me "love" all the time. That annoys me. You would not be calling me "love" if I was a male colleague.

Now as I reflect on these situations, gender actually affects a lot of what I do. I have to prove that I know what I am talking about just to get eye contact from male head coaches I have met on courses, for example, let alone get them to take on board what I am saying. On the first course I went on, we had to get into small groups to debate a particular topic and then present arguments back to the class. I remember being the only woman on the course, being called "lad" within five minutes, and my name not even being included in the presentation. After a lot of debate between the other head coaches in the group, I spoke up and answered one of their questions. As I talked, I saw this head coach sit up, he was the leader in our group, his neck went back and I could see the surprise written across his face like "oh, she might actually know what football is about and what she is doing." I would say that early coaching course experience had quite a negative influence on my confidence. You are certainly put in some uncomfortable situations, as I have described: men think that they are better than you, that they understand football more than you, and that they are a better head coach than you.

\section{Introduction to the Second Vignette: Work-Life Conflicts, Limited Career Mobility, and Marginalization}

In the second vignette, experiences of work-life conflicts, limited career mobility, and an ingrained system of prejudice in which men hold the power and women are largely excluded from career progression (i.e., marginalized) are explored. The talent development head coaches represented in this vignette described the organizational barriers they have faced in their efforts to further their coaching careers. The second vignette tells the story of Sarah, a full-time community head coach also working part-time as girls' academy head coach for a professional football club in England. Sarah described receiving a career-ending injury as a player and being encouraged by her father to get into coaching so that she could stay involved in football.

Sarah: A Talent Development Head Coach's Story (MidCareer). My life is football, football, football. I recently started coaching in the girls' academy at my club, in addition to juggling my full-time job in the community department. It is where I ultimately want to be full-time in the girls' academy, but the funding is only there as a part-time role so at the moment I work every day of the week apart from Sunday to fit it in. In the talent development stage of the football pyramid there is a lot of pressure from the club, my managers, players, and parents who all 
have a vested interest in my team performing well. I have probably taken on too much but being part of the women's game and having an impact on the future generation of potential England players is worth it.

I am one of only a few women head coaches in the girls' academy. I do feel that we are pushed towards coaching the younger age groups, and the male head coaches get to work exclusively with typically older, and better, age groups. Having women head coaches as role models for the older players is just as important as the younger players, and I am just as qualified as my male colleagues, so it is upsetting that there is such limited opportunity to progress in my career here without any apparent explanation. I experienced this a few years ago when I worked as a boys' academy head coach with a professional club. I was on lots of short-term contracts and I wanted to apply for the permanent position the club decided to create. My line manager told me I could not apply for the position because the club did not want to hire women to coach in elite talent development. I asked him why he employed me on lots of short-term contracts if I was not a good enough head coach in the first place. He had no reply. I left and joined another academy. But even with that job, I initially had to go through three levels of management to secure the position because the senior head coaches initially did not want to employ me because I had children and they assumed I would call in sick quite a lot because of it. It was such a kick in the teeth. I felt there was just barrier after barrier to career progression.

Over the last few years there have definitely been improvements to the coaching opportunities available to women and the breakdown of some barriers. In my opinion, it is going to be another couple of decades to change the mindset in this country to the point women are fully represented in the coaching workforce. If you look at the typical age of coach educators, they are mid-50s and have grown up with a stereotypical philosophy towards women in football, and we simply have to wait for them to move on. I have been called "lad" and "boy" on coaching courses so many times I could not count them all. They probably do not even realize they are doing it. Little things like the use of gendered language on courses can make a big difference to women like me. At the last course I went on I challenged the male tutor on this. He had said once we had completed a group task "one of you boys can present back to the class." So, I said "okay, I will not present then." He changed his language the next time to "one of you people." I think he was just ignorant to what he had said and did not really know what he should be saying in those moments. Unfortunately, in my experience not all women head coaches I know have the confidence to speak up like that.

\section{Introduction to the Third Vignette: Realities of Elite Level Football, Prevalent Undercurrents of Sexism, and Apprehensions About Future Directives}

In the third vignette, the realities of working at an elite level of football are explored in addition to concerns for the implementation of future directives that promote women coaches. The elite women head coaches represented in this third vignette described the development of an undercurrent of sexism which has substituted overt discrimination of the past, their use of affirmative action to their advantage, and their apprehensions about future directives that aim to increase the number of women head coaches in football. The third vignette tells the story of Emily, a woman coach educator and head coach of a women's team for a semi-professional club in England. Emily played international football from the age of 12 years and described being inspired to get into coaching by her coaches once her playing career ended.

Emily: An Elite Head Coach's Story (Late Career). Elite football is another world, it is ruthless and tough for any head coach, let alone a woman head coach. I am completely numb to it now and I know I am fortunate to be surrounded by supportive head coaches in the professional club I currently work in, but I was not always. As a woman head coach at an elite level, whether that's in men's or women's football, you are under enormous pressure to consistently deliver results for the financial performance and reputation of the club. In one of the first men's professional academy jobs that I had, one of my male colleagues kept undermining my position as head coach. When I offered to make a cup of tea for my colleagues, he shouted across the room, "Is that not what you are actually employed to do, to go into the kitchen and make us a cup of tea?" I went home and thought, do I really have to deal with this on top of the pressures of the job? It really got to me. I was shocked by what he said but knew I had to stand up for myself and call him out on his sexist comments, which I did. He never made another comment again. But it did knock my confidence. I kept wondering what head coaches might be saying behind my back and questioning whether I deserved to be in that academy role. I felt I had to work twice as hard to get half the recognition my male colleagues did in that job. But the reality is, as women in elite football, we are always going to have to constantly prove ourselves because of our lack of numbers, although women's football in my opinion is more inclusive.

It is so important for women coaches wanting to work at the elite level [of the football pyramid] to be aware of the realities of that workplace. Over the years, even in my current role in charge of a semi-professional women's team, I have grown to expect little comments, odd looks, or lack of any conversation in my direction because of my gender. I do think [gender discrimination] is getting better though, I do not tend to hear derogatory comments, noticeably since I gained employment in women's football. You do, however, know when a male colleague is acting differently around you, looking down upon you, or feels superior to you. I have experienced that a lot in football; men feeling insecure around me and trying to assert their dominance with sexist "banter" either in the dugouts on a matchday or around the training ground. I think a lot of head coaches are ignorant, they do not realize what they are saying is not playful humor and can be hurtful to others taken out of context. Even a male referee has acted this way with me. Having experienced both, there is a big difference between making a flippant comment and being ignorant about the effect it has, and someone saying something discriminatory on purpose.

I am also a coach educator and act as a course tutor on the NGB's coaching courses. I can guarantee that $99 \%$ of the courses that I tutor on, all of the candidates are men. Every course tutor has to prove they are an expert head coach to their candidates when they are a running a course, but I already know before I step into the room that I will be on the back foot the moment I walk in and they see a woman tutor. I have had candidates do a double take and look at me twice because in front of them is a woman that does not fit their stereotypical view of women and football. I would say a woman head coach in a male-dominated sport like football has had to develop more skills than her male counterpart for that very reason. I have good coping skills, I am thick skinned, and I process information before I act on it. I know that, because of my gender, if I say something wrong, and it is compared to the same situation with a male colleague, my club would come down on me like a ton of bricks more so than they would him. You do get labeled as the token woman, but to be honest I am okay with that if it gets me 
somewhere I want to go, because once I interact with people I prove why I am here.

My biggest worry at the moment is that clubs are motivated to employ a woman head coach because they want to "tick a box" for the governing body, not because they are interested in creating a diverse workforce. If those head coaches are not good enough, they should not be there-men or women. We need the right people. I am $100 \%$ in support of encouraging women head coaches into football and having networking opportunities as we are often isolated from other women in our coaching jobs. But I have mixed feelings about this if I am honest. The more we brand ourselves as women head coaches, the more everybody else will do so, instead of as head coaches. For instance, I know there are women-only UEFA B coaching courses now but I would never opt to go on one of those. I would choose the mixed gender course because I would learn more from having a mix of men and women candidates with a diverse range of experiences that contribute to the course. I do understand some women are intimidated by traditionally male-run coaching courses. Another example I could give is the women coaching conference I recently attended. It was fantastic to see all of these women head coaches from different sports in one place, and I enjoyed being able to talk to other women with similar experiences. But I sat there thinking, why not have a coaching conference with all big-name women guest speakers that both men and women attend to mingle with each other? I believe the more I call myself a female coach, the more other people will call me a female coach when really, I am just a coach.

\section{Discussion}

Through the novel presentation of vignettes, the consistent impact of gender in the football workplace was illuminated, which facilitated a deeper insight to, and extended our understanding of, the numerous sociocultural and organizational barriers women head coaches face in specific occupational areas. It was revealed that (a) women head coaches experience isolation and a lack of confidence, and have to fight for equipment and resources in youth recreational football (vignette 1), (b) gendered organizational practices take place that limit career mobility of women coaches and place extra pressure on them to develop players into elite performers (vignette 2), and (c) "token" women face increased scrutiny at the elite level to consistently deliver results and are concerned with initiatives that are heavily dependent on preferring female candidates over male candidates (i.e., positive gender discrimination) (vignette 3). Overall, these results support the theoretical tenet of hegemonic masculinity in the football workplace and make two significant contributions to the literature. First, we present an in-depth examination of what football coaching means as a woman at the organizational and sociocultural levels of LaVoi and Dutove's (2012) ecological model. Second, we facilitate new understandings of the issues that shape women coaches' navigation of gender in the football workplace through the novel methodological approach of creative nonfiction.

The first vignette (Janet) indicated women head coaches resist, challenge, and transform expectations of hegemonic masculinity in recreational football from early in their career. Janet described uncomfortable experiences with male players and head coaches at her club and at league committee meetings, demonstrating that football as an institution is a ground for sexism and privileges dominant masculinity (Pringle, 2005). As the only woman head coach in her club, Janet was isolated with minimal support but demonstrated resistance to restrictive power relations in football culture by ensuring that her players felt equal to their male peers and had equal access to resources and equipment. Access to few resources and minimal support have been cited by former women coaches in recreational football as reasons for leaving the coaching profession, especially early in their career (Cunningham, Sagas, Dixon, Kent, \& Turner, 2005; Kamphoff, 2010). In the development of their ecological model, LaVoi and Dutove (2012) contend that a perceived absence of support for women coaches (an interpersonal barrier) results in a lack of upward mobility. The early career women coaches who participated in this study worked in organizations without adequate support, suggesting that access to few resources is also a multidimensional barrier existing at the organizational level of the ecological model. Hence it is crucial that initiatives be put in place to increase women coaching networks and role models to ensure women, such as Janet, do not feel isolated, have adequate support, and do not leave recreational football or the coaching profession early in their career. Despite their existence, researchers know little about the adoption by sports organizations of formal women coach mentor schemes that match promising early-career coaches with established coaches. For example, the FA's coach mentor program offers on-ground personalized support to all recreational coaches across the country. Building awareness among women coaches is imperative so coaches like Janet are aware of support structures from early in their career.

Janet's lack of experience with other women coaches may be due to a distinct shortage of experienced coaches available to serve as mentors. As Emily identified, experienced women coaches already feel as though they have to work twice as hard to get half the amount of recognition and may not have the time to spend mentoring others. Given the extra time burden mentoring may place on women coaches, NGBs should boost the inclusion of men as cross-gender mentors to buffer women coaches from overt sexism and help their mentee to circumvent structural, social, and cultural barriers to career advancement (Sagas \& Cunningham, 2004). Male mentors are also more likely to be in influential decision-making positions than women and able to assist the career development of women coaches (Weaver \& Chelladurai, 2002). Shadowing a mentor is likely to provide substantial benefits such as positively influencing Janet's career expectations and goals, and by providing Janet exposure and networking opportunities at professional conferences (Cunningham et al., 2005). In their model, LaVoi and Dutove (2012) summarize mentoring as both a potential interpersonal level barrier and support for women coaches. This body of work has largely examined mentoring functions from only the mentee's perspective and omitted the mentors, whose ability to provide support can be diminished by high workloads and pressure to perform at high levels (Bower, 2011). Researchers must address this important gap in knowledge to understand the leadership behaviors that best support mentee's advancement.

In line with previous research (e.g., Lewis et al., 2018), Janet perceived the coach education atmosphere to be intimidating and uncomfortable. In particular, male coach educators maintain the status quo in football culture by sustaining dominant beliefs and practices associated with the exclusion of women coaches. A major shortage of women coach educators exists in England; women represent only $3 \%$ of all coaches with the minimum FA Level 3 coaching qualification required to become an FA coach educator (Union of European Football Associations, 2017). The Professional Football Association (PFA) only appointed their first woman coach educator, former England manager Hope Powell, in 2016 (Press Association, 2016). In addition to implementing strategies to 
increase the number women coach educators (e.g., concessions for UEFA-level courses and promotional campaigns), gender equality training should be implemented within annual continuous professional development events for coach educators to ensure that those in charge of coach education courses possess the knowledge and tools to provide an unthreatening environment for women during coach education programmes.

In the second vignette (Sarah), women head coaches described gendered organizational practices that limited their career mobility. The deeply masculine nature of the professional football clubs that Sarah experienced advantaged men in hiring, denied women career advancement, and perpetuated women's underrepresentation in the football workplace. A novel finding to this study was that the gender-based allocation of organizational positions in the talent development stage of the football pyramid entrapped Sarah to coaching younger age groups, reflecting the strength of gender stereotypes surrounding women's work and that women are naturally better suited to low status roles (Kane \& Stangl, 1991). It is evident that when women are placed in less desirable positions than men at talent development stages, marginalization occurs through persistent absence at the elite level (Kanter, 1977). Being restricted to roles that are consistent with gender norms (e.g., maternal nurturing of younger players; Welford, 2011) is a barrier to career mobility for women football coaches who have more to offer but have no avenue to do so. This practice is a double standard-men have been integrated within women's sport, yet women remain restricted from men's sport (Walker \& Bopp, 2010). Women like Sarah bring professional qualifications and coaching expertise plus increasing experience of playing women's football to offer female players. We purport that football organizations should consider women as an untapped resource and coordinate with governing bodies to open the closed routes experienced by women head coaches in this study to transform recruitment transparency and accountability. Changes may include appointment protocols and clear publicized selection criteria to assess candidates and justify decisions in relation to gender (Van den Brink, Benschop, \& Jansen, 2010).

Sarah's lack of belief in her abilities could be linked to the deep structure of gender inequality in talent development football. Sarah described complex working environments which were outside of simple resistance and reproduction of hegemonic masculinity, but instead were spaces where women and men negotiated power in multiple ways. Being in a sociocultural environment where patriarchal devaluing of women in sport occurs can have an eroding impact on women head coaches' self-confidence (Norman, 2014), who often have lower self-confidence than men (Cunningham, Doherty, \& Gregg, 2007). Sarah is at a crossroads in her career; under pressure to produce elite performers after coaching football for five years, the average length of time when women typically leave the profession (Cunningham \& Sagas, 2003). This is a structural turning point in her career (Hodkinson \& Sparkes, 1997), typified by movement from an early professional to an established top-level coach (Barker-Ruchti, Lindgren, Hofmann, Sinning, \& Shelton, 2014). She has moved from part-time to fulltime coaching, under pressure from stakeholders in the talent development stage of the football pyramid to mold players into elite level performers, and is in a demanding phase where work-life balance is often compromised (Dixon \& Bruening, 2007). Previous evidence on work-family balance identified in LaVoi and Dutove's (2012) ecological model suggests that women coaches negotiate work-family balance more easily when single and without children (Reade et al., 2009). Our finding adds to our existing knowledge on work-life conflict by providing contextual insights on gendered experiences of mid-career coaches in the unique context of talent development football.

Sarah's story also highlights the pattern of normative practice that has allowed men's dominance over women in football to continue, as well as how the theory of hegemonic masculinity makes sense of gender diversity and sameness in the football workplace. That is, Sarah recalled men asserting their dominance in football knowledge, that they were naturally superior, and were better coaches than women like her (Messner, 1992). Sarah documented that the costs of hegemony to her were a compromised work-life balance and limited career mobility. Our study adds to a body of evidence that suggests sport is one of the most visible contexts where hegemonic masculinity is reproduced (Krane, 2001; Satore \& Cunningham, 2007). Within this context, women in football are, however, challenging the acceptable gender boundaries and serve to disrupt the male-defined, suitable behaviors of women. The addition of resistance from patriarchal organizations to Sarah's presence could have led to her leaving the profession at this crucial stage of her career. At this level of the football pyramid coaches are typically appointed if they hold the FA Level 3 qualification with relevant coaching experience or FA Level 2 coaching qualification with significant elite level playing experience. Gender diversity decreases at this level of the football pyramid: qualification transitions are such that women represent $4 \%$ of FA Level 2 qualified coaches and only $3 \%$ of FA Level 3 (i.e., UEFA B) qualified coaches (Union of European Football Associations, 2017). Therefore, organizations cannot ignore structural inequalities if they wish to keep these head coaches, who bring key skills such as enterprise in the face of adversity, within the profession. This may be in the form of opening their practices to independent researchers to discover how women in their organization strategically negotiate their work and life responsibilities and its consequences on career progression to get to the crux of why some women stay while others leave coaching at talent development levels of football. This finding adds to our theoretical knowledge of barriers for women coaches identified by LaVoi and Dutove (2012) with the addition of job distributions at the organizational level.

The third vignette (Emily) revealed "token" women face increased scrutiny at elite levels and are concerned by positive gender discrimination. Elite level coaching can be particularly isolating for women when historically there has been limited access to leadership positions and minimal existence of old girls networks (Norman, 2008; Talbot, 2002). Despite this, Emily firmly believed that men and women head coaches should only be advanced if they held the right expertise. At this level of the football pyramid, coaches are typically appointed if they possess the FA Level 5 (i.e., UEFA Pro) coaching qualification, or the FA Level 4 (i.e., UEFA A) qualification with relevant coaching (or playing) experience. Qualification transitions are such that the negative trend at the talent development level continues at the elite level and gender diversity decreases further: women represent $2 \%$ of FA Level 4 qualified coaches and $1.5 \%$ of FA Level 5 qualified coaches (Union of European Football Associations, 2017). Emily expressed her concerns that organizations might be pressured by NGBs to focus on increasing their number of women head coaches rather than employing those with the required expertise. Numeric balancing has been argued to be too simplistic a solution that might exacerbate the situation rather than solve it (Norman, 2008; Theberge, 1993). Another finding of this study was that Emily interestingly viewed her token status positively, if it got her "foot in the door" and gave 
her access to people in power, she was confident her coaching expertise would shine through and surpass her gender. This perhaps helps to explain why Emily did not want to be known as a woman head coach and would not choose to attend single gender courses that often have the connotation of lesser standards (Fielding-Lloyd \& Meân, 2008). It is not surprising that Emily did not want to be viewed as an outsider unable to achieve the necessary (male) standard, nor be seen as needing extra help to achieve the same goals as her male colleagues. This finding is novel in that it is in direct contrast to that of previous research of Lewis et al. (2018) that $80 \%$ of women football head coaches interviewed were in support of women-only coaching courses. However, we recognize that what differs is that Lewis et al.'s participants worked at various levels of the football pyramid, whereas our head coaches' view might be shaped by occupation in elite football.

A distinct finding was that women coaches operating at the elite level of the football pyramid did not want to create a dichotomy of "us" and "them." Separatism between genders can reinforce differentiation and the absence of women from these environments, meaning that male-dominated norms are not challenged, but perpetuate gender inequality (Fielding-Lloyd \& Meân, 2008). Critics of this perspective might suggest that, by striving for sameness, the hegemonic male standard is reinforced as the norm and women ultimately conform to the inequality gender practices that they wish to reject (Shaw \& Hoeber, 2003). Emily's story highlights how new configurations to women's identity and practice as professional coaches in the football workplace can impact the traditional gender hierarchies. Emily described being accepted by her peers once initiated in their culture, but women must remember that hegemonic masculine patterns can change by incorporating elements from others (Connell \& Messerschmidt, 2005). In respect of this, elite level coaches should perhaps exercise caution in (unintentionally) encouraging other women coaches to behave similarly to their male counterparts. Emily's views differed from Sarah's and Janet's regarding gender support, demonstrating differences in opinion depending on the stage(s) of career development and specific occupational area. NGBs should note, therefore, that gendered support for head coaches (e.g., women-only coaching courses) was supported by the head coaches in the earlycareer and mid-career vignettes, and a targeted approach delivered consistently across regional football associations towards women at early-mid stages of their careers and operating at lower levels of the football pyramid is recommended. This finding adds to our theoretical knowledge of supports for women coaches identified by LaVoi and Dutove (2012) with the addition of occupationaltargeted gendered support at the organizational level of analysis.

Furthering emerging research by Lewis et al. (2018), all women interviewed noted that the repetitive adoption of language which was insensitive and which reinforced gender stereotypes that the head coaches were trying to resist. Whilst women might be motivated to disprove gender stereotypical beliefs of male coach educators, research has shown that women's excessive achievement concern can impair their performance (e.g., Hively \& ElAlayli, 2014). Being called "lad" or "boy" was frequently reported by women head coaches, and based on their accounts, coach education courses privileged male needs and ideals of coaching, thereby denying them the opportunity to explore alternative styles which might better suit them (Welford, 2011). This approach assumes that the responsibility is on women to fit within highly gendered cultural practices of coach education provision, rather than for such practices to adapt and change. All women reported recent experiences of sexism despite the NGB's drive to increase the number of women coaches in football. NGBs and researchers should further interrogate the cultural practices that underpin the stories presented here by consulting women coaches on their developmental needs as women operating in occupational areas outside of patriarchal norms.

\section{Limitations}

Several limitations should be acknowledged. First, by highlighting commonalities between women coaches, the experiences of women from other marginalized social identities were not explored (e.g., race, sexual orientation, education, and socioeconomic status). Future work may wish to draw attention to understanding how other identities interact with gender (i.e., intersectionality) to produce different experiences in the football workplace. Second, semistructured interviews were employed within this study to allow for flexibility in theme elicitation, however there is no perfect genre of data representation in qualitative research (Smith et al., 2015), and researchers might wish to consider life histories as a methodology to permit greater exploration of the specific themes that this study highlights over time. Third, our study is limited to the binary conceptualization of men and women, future research should go beyond masculinity and femininity hierarchy to integrate hegemonic masculinity into the illustration of cultural practices in football. Lastly, we acknowledge that the classification of each participant's occupational area was no perfect grouping. However, as BarkerRuchti et al. (2014) argued, any classifications are a flawed system as linear development and stages of career that all women pass through does not exist. Some themes existed across levels of the football pyramid, for example evidence of gender bias (e.g., having to prove yourself) appeared in more than one vignette. It is not surprising that overlapping themes existed, given the elite level coaches are likely to have been recreational coaches in an earlier stage of their career. The relevance of the themes to each occupational area was determined by their prevalence among the participants' spoken words. For example, both Janet and Emily mentioned gender bias in their accounts, however Janet not only spoke about this bias to a much greater extent than Emily but also described the current gender bias she experienced as negatively impacting her wellbeing, whereas Emily did not. By presenting separate vignettes based on stages of career, we open the capacity to multiple understandings of how gender permeates the workplace, and how this is differentiated by career experiences and life perspectives, extending previous literature. Researchers may wish to consider the background of women coaches to understand how they have arrived at critical points in their career. In the future, it may also be prudent to expand this line of enquiry in football from women head coaches to whether gender inequality stretches across other roles in football with similar increased scrutiny (e.g., women match officials).

\section{Conclusion}

In summary, the present work highlights the consistent impact of gender for women in the football workplace: negatively influencing head coaches' interactions and confidence early in their career and in youth recreational football, embedded within discriminatory organizational practices which limit career mobility, and used to hold elite level head coaches to higher scrutiny levels than male colleagues. This study corroborates hegemonic masculinity as a valid theoretical lens to the study of women coaches and maledominated sports (e.g., football) at the sociocultural level of analysis, and adds occupational-focused gendered provision as a 
support at the organizational level of LaVoi and Dutove's (2012) ecological model. By gaining deeper insights into the numerous sociocultural and organizational barriers women head coaches face during their careers using creative nonfiction to tell first hand stories, this study offers governing associations reasons to move away from a present "one size fits all" approach to supporting women head coaches, and towards a targeted approach by career stages and specific occupational areas to aid their career progression.

\section{Note}

1 The FA's coach education pathway maps the learning journey from an introduction to coaching with the FA Level 1 in coaching football, through to the advanced qualification required in elite football, the FA Level 5 in coaching football (Football Association, 2016).

\section{References}

Barker-Ruchti, N., Lindgren, E.C., Hofmann, A., Sinning, S., \& Shelton, C. (2014). Tracing the career paths of top-level women football coaches: Turning points to understand and develop sport coaching careers. Sports Coaching Review, 3(2), 117-131. doi:10.1080/ 21640629.2015.1035859

Bourdieu, P. (1986). Distinction. A social critique of the judgement of taste. London: Routledge.

Bourke, B. (2014). Positionality: Reflecting on the research process. The Qualitative Report, 19(33), 1-9.

Bower, G.G. (2011). The examination of the mentoring relationship between the head coach and assistant coaches of women's basketball teams. Advancing Women in Leadership, 31, 1-7. doi:10.18738/awl. v31i0.66

Braun, V., \& Clarke, V. (2006). Using thematic analysis in psychology. Qualitative Research in Psychology, 3(2), 77-101. doi:10.1191/ 1478088706qp063oa

Braun, V., Clarke, V., \& Weate, P. (2016). Using thematic analysis in sport and exercise research. In B. Smith, \& A. Sparkes (Ed.), Routledge Handbook of Qualitative Research in Sport and Exercise, 191-205. London: Routledge.

Bryson, L. (1987). Sport and the maintenance of masculine hegemony. Women's Studies International Forum, 10(4), 349-360. PubMed ID: 31344717 doi:10.1016/0277-5395(87)90052-5

Burton, L.J. (2015). Underrepresentation of women in sport leadership: A review of research. Sport Management Review, 18(2), 155-165. doi:10.1016/j.smr.2014.02.004

Burton, L.J., \& LaVoi, N.M. (2016). An ecological/multisystem approach to understanding and examining women coaches. In N.M. LaVoi (Ed.), Women in sports coaching. Oxfordshire, UK: Routledge.

Caudwell, J. (2011). Gender, feminism and football studies. Soccer \& Society, 12(3), 330-344.

Christensen, M.K. (2013). Outlining a typology of sports coaching careers: paradigmatic trajectories and ideal career types among highperformance sports coaches. Sports Coaching Review, 2(2), 98-113. doi:10.1080/21640629.2014.898826

Connell, R.W. (1987). Gender and power. Palo Alto, CA: Stanford University Press.

Connell, R.W., \& Messerschmidt, J.W. (2005). Hegemonic masculinity: Rethinking the concept. Gender \& Society, 19(6), 829-859. doi:10. 1177/0891243205278639
Cunningham, G.B., Doherty, A.J., \& Gregg, M.J. (2007). Using social cognitive career theory to understand head coaching intentions among assistant coaches of women's teams. Sex Roles, 56(5-6), 365-372. doi:10.1007/s11199-006-9175-z

Cunningham, G.B., \& Sagas, M. (2003). Occupational turnover intent among assistant coaches of women's teams: The role of organizational work experiences. Sex Roles, 49(3-4), 185-190. doi:10.1023/A: 1024469132536

Cunningham, G.B., Sagas, M., Dixon, M., Kent, A., \& Turner, B.A. (2005). Anticipated career satisfaction, affective occupational commitment, and intentions to enter the sport management profession. Journal of Sport Management, 19(1), 43-57. doi:10.1123/jsm. 19.1 .43

Dixon, M.A., \& Bruening, J.E. (2007). Work-family conflict in coaching I: A top-down perspective. Journal of Sport Management, 21(3), 377406. doi:10.1123/jsm.21.3.377

Durand-Bush, N., Collins, J., \& McNeill, K. (2012). Women coaches' experiences of stress and self-regulation: A multiple case study. International Journal of Coaching Science, 6(2), 21-43.

Eagly, A.H., \& Karau, S.J. (2002). Role congruity theory of prejudice toward female leaders. Psychological Review, 109(3), 573-598.

Fielding-Lloyd, B., \& Meân, L.J. (2008). Standards and separatism: The discursive construction of gender in English football coach education. Sex Roles, 58(1-2), 24-39. doi:10.1007/s11199-0079334-X

Fielding-Lloyd, B., \& Meân, L.J. (2011). 'I don't think I can catch it': Women, confidence and responsibility in football coach education. Soccer \& Society, 12(3), 345-364. doi:10.1080/14660970.2011. 568102

Filho, E., \& Rettig, J. (2018). The road to victory in the UEFA Women's Champions League: A multi-level analysis of successful coaches, teams, and countries. Psychology of Sport and Exercise, 39, 132-146. doi:10.1016/j.psychsport.2018.07.012

Fink, J.S., LaVoi, N.M., \& Newhall, K.E. (2016). Challenging the gender binary? Male basketball practice players' views of female athletes and women's sports. Sport in Society, 19(8-9), 1316-1331. doi:10.1080/ 17430437.2015.1096252

Fishwick, N. (1989). English football and society: 1910-1950. Manchester, UK: Manchester University Press.

Football Association. (2014). Respect codes of conduct. London, UK: The Football Association.

Football Association. (2016). Discover the coaching pathway from grassroots to elite level. Retrieved from http://www.thefa.com/news/2016/ oct/07/discover-the-coaching-pathway

Football Association. (2017a). FA to restructure women's football pyramid at elite level. Retrieved from http://www.thefa.com/news/2017/ sep/26/fa-restructure-womens-football-pyramid-wsl-wpl-270917

Football Association. (2017b). The gameplan for growth: The FA's strategy for women's and girls' football: 2017-2020. London, UK: Author.

Gramsci, A. (1971). Selections from the prison notebooks. New York, NY: International Publishers.

Hings, R.F., Wagstaff, C.R., Anderson, V., Gilmore, S., \& Thelwell, R.C. (2018). Professional challenges in elite sports medicine and science: Composite vignettes of practitioner emotional labor. Psychology of Sport and Exercise, 35, 66-73. doi:10.1016/j.psychsport.2017. 11.007

Hively, K., \& El-Alayli, A. (2014). "You throw like a girl:" The effect of stereotype threat on women's athletic performance and gender stereotypes. Psychology of Sport and Exercise, 15(1), 48-55. doi:10.1016/j. psychsport.2013.09.001 
Hodkinson, P., \& Sparkes, A.C. (1997). Careership: A sociological theory of career decision making. British Journal of Sociology of Education, 18(1), 29-44. doi:10.1080/0142569970180102

Hoeber, L., \& Shaw, S. (2017). Contemporary qualitative research methods in sport management. Sport Management Review, 20(1), 4-7. doi:10.1016/j.smr.2016.11.005

Kamphoff, C.S. (2010). Bargaining with patriarchy: Former female coaches' experiences and their decision to leave collegiate coaching. Research Quarterly for Exercise and Sport, 81(3), 360-372. PubMed ID: 20949856

Kane, M.J., \& Stangl, J.M. (1991). Employment patterns of female coaches in men's athletics: Tokenism and marginalization as reflections of occupational sex-segregation. Journal of Sport and Social Issues, 15(1), 21-41. doi:10.1177/019372359101500102

Kanter, R.M. (1977). Some effects of proportions on group life: Skewed sex ratios and responses to token women. American Journal of Sociology, 82(5), 965-990. doi:10.1086/226425

Krane, V. (2001). We can be athletic and feminine, but do we want to? Challenging hegemonic femininity in women's sport. Quest, 53(1), 115-133. doi:10.1080/00336297.2001.10491733

LaVoi, N.M. (2016). A framework to understand experiences of women coaches around the globe: The Ecological-Intersectional model. In N.M. LaVoi (Ed.), Women in sports coaching (pp. 13-34). New York, NY: Routledge.

LaVoi, N.M., \& Dutove, J.K. (2012). Barriers and supports for female coaches: An ecological model. Sports Coaching Review, 1(1), 17-37. doi:10.1080/21640629.2012.695891

Lewis, C.J., Roberts, S.J., \& Andrews, H. (2018). 'Why am I putting myself through this?' Women football coaches' experiences of the Football Association's coach education process. Sport, Education and Society, 23(1), 28-39. doi:10.1080/13573322. 2015.1118030

McCorkel, J.A., \& Myers, K. (2003). What difference does difference make? Position and privilege in the field. Qualitative Sociology, 26(2), 199-231. doi:10.1023/A:1022967012774

McCoyd, J.L., \& Kerson, T.S. (2006). Conducting intensive interviews using email: A serendipitous comparative opportunity. Qualitative Social Work, 5(3), 389-406.

Messner, M.A. (1992). Power at play: Sports and the problem of masculinity. Boston, MA: Beacon.

Newsham, G.J. (1994). "In a league of their own”: Dick Kerr Ladies Football Club 1917-1965. Chorley, UK: Pride of Place Publishing.

Norman, L. (2008). The UK coaching system is failing women coaches. International Journal of Sports Science \& Coaching, 3(4), 447-476. doi:10.1260/174795408787186431

Norman, L. (2014). A crisis of confidence: Women coaches' responses to their engagement in resistance. Sport, Education and Society, 19(5), 532-551. doi:10.1080/13573322.2012.689975

Norman, L., Rankin-Wright, A.J., \& Allison, W. (2018). "It's a concrete ceiling; It's not even glass": Understanding tenets of organizational culture that supports the progression of women as coaches and coach developers. Journal of Sport and Social Issues, 42(5), 393-414. doi:10.1177/0193723518790086

Novick, G. (2008). Is there a bias against telephone interviews in qualitative research?Research in Nursing \& Health, 31(4), 391-398.

NVivo Qualitative Data Analysis Software. Version 11. (2015). QSR International Pty Ltd.

Press Association. (2016). Hope Powell named PFA's first female coach educator. Retrieved from https://www.theguardian.com/football/ 2016/apr/05/hope-powell-named-pfa-first-female-coach-educator

Pringle, R. (2005). Masculinities, sport, and power: A critical comparison of Gramscian and Foucauldian inspired theoretical tools. Journal of Sport and Social Issues, 29(3), 256-278. doi:10.1177/ 0193723505276228

Reade, I., Rodgers, W., \& Norman, L. (2009). The under-representation of women in coaching: A comparison of male and female Canadian coaches at low and high levels of coaching. International Journal of Sports Science \& Coaching, 4(4), 505-520. doi:10.1260/ 174795409790291439

Reinharz, S., \& Davidman, L. (1992). Feminist methods in social research. New York, NY: Oxford University Press.

Rudd, A. (2018). Is football ready for women coaches? Retrieved from https://www.thetimes.co.uk/article/is-football-ready-for-women-coacheshvpm20nrb

Sagas, M., \& Cunningham, G. (2004). The impact of supervisor support on perceived career outcomes of the senior woman administrator. International Journal of Sport Management, 5, 229-242.

Sartore, M.L., \& Cunningham, G.B. (2007). Explaining the underrepresentation of women in leadership positions of sport organizations: A symbolic interactionist perspective. Quest, 59, 244-265. doi:10.1080/ 00336297.2007.10483551

Schinke, R.J., Blodgett, A.T., McGannon, K.R., \& Ge, Y. (2016). Finding one's footing on foreign soil: A composite vignette of elite athlete acculturation. Psychology of Sport and Exercise, 25, 36-43. doi:10. 1016/j.psychsport.2016.04.001

Scraton, S., Fasting, K., Pfister, G., \& Bunuel, A. (1999). It's still a man's game? The experiences of top-level European women footballers. International Review for The Sociology of Sport, 34(2), 99-111. doi:10.1177/101269099034002001

Shaw, S., \& Allen, J.B. (2009). The experiences of high-performance women coaches: A case study of two Regional Sport Organisations. Sport Management Review, 12(4), 217-228. doi:10.1016/j.smr.2009. 03.005

Shaw, S., \& Hoeber, L. (2003). "A strong man is direct and a direct woman is a bitch": Gendered discourses and their influence on employment roles in sport organizations. Journal of Sport Management, 17(4), 347-375. doi:10.1123/jsm.17.4.347

Smith, B. (2013). Sporting spinal cord injuries, social relations, and rehabilitation narratives: an ethnographic creative non-fiction of becoming disabled through sport. Sociology of Sport Journal, 30(2), 132-152. doi:10.1123/ssj.30.2.132

Smith, B., \& McGannon, K.R. (2018). Developing rigor in qualitative research: Problems and opportunities within sport and exercise psychology. International Review of Sport and Exercise Psychology, 11(1), 101-121. doi:10.1080/1750984X.2017.1317357

Smith, B., McGannon, K.R., \& Williams, T.L. (2015). Ethnographic creative nonfiction. In G. Molnar \& L.G. Purdy (Eds.), Ethnographies in sport and exercise research. London, UK: Routledge.

Smith, B., \& Sparkes, A.C. (2016). Routledge handbook of qualitative research in sport and exercise. Oxford, UK: Taylor \& Francis.

Stride, A., Fitzgerald, H.F., \& Allison, W. (2017). A narrative approach: The possibilities for sport management. Sport Management Review, 20(1), 33-42. doi:10.1016/j.smr.2016.10.002

Talbot, M. (2002). Playing with patriarchy: The gendered dynamics of sports organizations. In S. Scraton \& A. Flintoff (Eds.), Gender and sport: A reader. London, UK: Routledge.

Temple, B., \& Young, A. (2004). Qualitative research and translation dilemmas. Qualitative Research, 4(2), 161-178. doi:10.1177/ 1468794104044430

Theberge, N. (1993). The construction of gender in sport: Women, coaching, and the naturalization of difference. Social Problems, 40(3), 301-313. doi:10.2307/3096881

The Culture, Media, and Sport Committee. (2006). Women's football: Fourth report of session 2005-06. London, UK: The House of Commons. 
Tomkins, J. (1993). The football discourse: The generation and control of the male and female body and its impact on the football world. In C. Brackenridge (Ed.), Body matters: Leisure images and lifestyles. Eastbourne, UK: Leisure Studies Association.

Tracy, S.J. (2010). Qualitative quality: Eight "big-tent" criteria for excellent qualitative research. Qualitative Inquiry, 16(10), 837-851. doi:10.1177/1077800410383121

Union of European Football Associations. (2015). Women's football across the national associations 2014-15. Retrieved from http:// www.uefa.com/MultimediaFiles/Download/Women/General/02/03/ 27/84/2032784_DOWNLOAD.pdf

Union of European Football Associations. (2017). Women's football across the national associations 2016-17. Retrieved from http://www.uefa. com/MultimediaFiles/Download/OfficialDocument/uefaorg/Women \%27sfootball/02/43/13/56/2431356_DOWNLOAD.pdf

Van den Brink, M., Benschop, Y., \& Jansen, W. (2010). Transparency in academic recruitment: A problematic tool for gender equality? Organization Studies, 31(11), 1459-1483. doi:10.1177/0170840610380812

Walker, N.A., \& Bopp, T. (2010). The underrepresentation of women in the male-dominated sport workplace: Perspectives of female coaches. Journal of Workplace Rights, 15(1), 47-64. doi:10.2190/WR.15.1.d
Weaver, M.A., \& Chelladurai, P. (2002). Mentoring in intercollegiate athletic administration. Journal of Sport Management, 16, 96-116. doi:10.1123/jsm.16.2.96

Welford, J. (2011). Tokenism, ties and talking too quietly: Women's experiences in non-playing football roles. Soccer \& Society, 12(3), 365-381. doi:10.1080/14660970.2011.568103

Williams, J. (2003). The fastest growing sport? Women's football in England. Soccer \& Society, 4(2-3), 112-127. doi:10.1080/ 14660970512331390865

Williams, J. (2013). A game for rough girls? A history of women's football in Britain. London, UK: Routledge.

Williams, J., \& Woodhouse, J. (1991). Can play will play? Women and football in Britain. In J. Williams \& S. Wagg (Eds.), British football and social change. Leicester, UK: Leicester University Press.

Women in Sport. (2016). Beyond 30\%: Female leadership in sport. Retrieved from https://www.womeninsport.org/wp-content/uploads/ 2017/10/Women-in-Sport-Beyond-3025-1-1.pdf?x99836

Wrack, S. (2018). 'What she says goes': meet the woman in charge of a men's team. Retrieved from https://www.theguardian.com/football/ blog/2018/dec/05/woman-in-charge-mens-team-football-arlesey-townnatasha-orchard-smith 